\title{
Groundwater Recharge Planning Using Field Survey for Talupula Mandal in Anantapur District, Andhra Pradesh, India
}

\author{
K. Nagamani*†, Prabhu Dass Batvari**, S. Packialakshmi***, C. Sai Kumar Reddy*** and \\ B. Anuradha***** \\ *Center for Remote Sensing \& Geoinformatics, Sathyabama Institute of Science \& Technology, Chennai, India \\ **Center for Earth and Atmospheric Science, Sathyabama Institute of Science \& Technology, Chennai, India \\ ***Department of Civil Engineering, Sathyabama Institute of Science \& Technology, Chennai, India \\ *****Chennai Institute of Technology, Chennai, India \\ †Corresponding author: K. Nagamani; nagamaniloganathan@gmail.com
}

Nat. Env. \& Poll. Tech.

Website: www.neptjournal.com

Received: 30-07-2021

Revised: 25-08-2021

Accepted: 03-09-2021

Key Words:

Groundwater

Recharge

Resistivity

Pseudo graphs

Semi-arid area

\begin{abstract}
Groundwater is essential to the sustainability of India's environment, economy, and living conditions because it isn't just the primary source of domestic supply of water in rural areas, but it is also the major and most productive origin of the water. The increased demand for groundwater as a result of reduced rainfall has put a strain on groundwater resources in areas where groundwater is the primary supply of water. The main aim of this study is to identify and explore the groundwater potential zones in Talupula Mandal of $280.3 \mathrm{~km}^{2}$ in Ananthapur district in Andhra Pradesh, India with semi-arid climatic conditions. Based on the field survey approach, groundwater availability is found out in the villages. Schlumberger Vertical Electrical Sounding (VES) survey technique was used to discover the resistivity and thickness of the unmistakable layers. It was carried out in 18 randomly selected sites where groundwater plays an important role in agricultural and domestic use. The thickness and resistivity of first- and secondlayer crack sites of the various layers were separated from ground data using IPI2WIN programming. Using software, graphs were plotted and groundwater potential zones were identified for recharging the groundwater. Based on the results, different models of recharge structures for the study area are identified and recommended. Hence the management of groundwater paves the way for sustainable groundwater levels.
\end{abstract}

\section{INTRODUCTION}

Groundwater is essential for the growth of the country's economy, ecosystem, and living standards. Groundwater movement in an area is influenced by topography, geological structure, lithology, the extent of the fracture, depth of weathering, slope, land use and land cover, drainage pattern, climatic conditions, and the interrelationships between these factors. Geology, soil texture, permeability, drainage intensity, soil depth, soil physiography, water holding capacity of the soil all influence the delineation of potential zones for both natural and artificial recharge (Alwathaf \& Mansouri 2011, George et al. 2011, Chandramohan et al. 2017). In semi-arid and arid zones, the problem of getting a sufficient supply of groundwater has always been a major concern of social orders. Even in zones with more and more abundant rainfall, the problem of getting a sufficient supply of groundwater is often turning out to be tougher due to increasing population and industrialization (Srinivasamoorthy et al. 2014, Zeinelabidin et al. 2015). As a result, this investigation focuses on options, as surface water cannot be relied upon on a constant basis, necessitating the search for other options to improve surface water (Vidhya \& Vinay 2018, Hammouri et al. 2013). As a result, the world is forced to rely on the most accessible source of high-quality freshwater, which is found underground as groundwater.

\section{Study Area}

Talupula Mandal is located in the Anantapur District's southeastern part in Andhra Pradesh which lies between $77^{0} 30^{\prime}-78^{0} 15^{\prime} \mathrm{E}$ and $14^{\circ} 0^{\prime}-14^{0} 30^{\prime} \mathrm{N}$ and it belongs to the Rayalaseema region. It is bounded on the west by Kadiri Mandal, on the south by Gandlapenta Mandal, on the north by Vemula Mandal, and on the east by Vempalle Mandal. The total population of Talupula Mandal is 42,019 living in 10,377 Houses, Spread across a total of 115 villages and 16 panchayats. Males are 21,451 and Females are 20,568. The climate in Talupulamandal is semiarid, with a moisture index of $33.7 \%$, with its monthly average temperatures ranging 
from $15^{\circ} \mathrm{C}$ in winter to $39^{\circ} \mathrm{C}$ in summer. The district's average precipitation is $553 \mathrm{~mm}$, which is the lowest in Andhra Pradesh when compared to other districts. The study area is shown in Fig.1.

\section{MATERIALS AND METHODS}

The study area and base map were prepared using Survey of India Topographical sheet nos. $57 \mathrm{~J} / 3, \mathrm{~J} / 4, \mathrm{~F} / 14, \mathrm{~F} / 15$. The Schlumberger Vertical Electrical Sounding (VES) method was used for the resistivity survey. The corresponding field study was conducted in 18 different locations. (Fig.2) in Talupula Mandal, where there is the availability of aquifers. The Schlumberger VES field survey was completed by dividing the electrode spacing by $100 \mathrm{~m}$. The spacing between the current electrodes $(\mathrm{AB} / 2)$ varied from 0.5 to $100 \mathrm{~m}$, while the spacing between the potential electrodes $(\mathrm{MN} / 2)$ varied from 0.5 to $10 \mathrm{~m}$. IPI 2 WIN software was used to convert the collected data into graphs, and the thickness and resistivity of various layers were determined.

\section{RESULTS AND DISCUSSION}

\section{Electric Resistivity}

Resistivity is a measure of how difficult it is to make an electrical current flow through it. It is also known as specific electrical resistance or volume resistivity, though these terms are less commonly used. Despite the fact that some materials are better than others at resisting the passage of electricity,

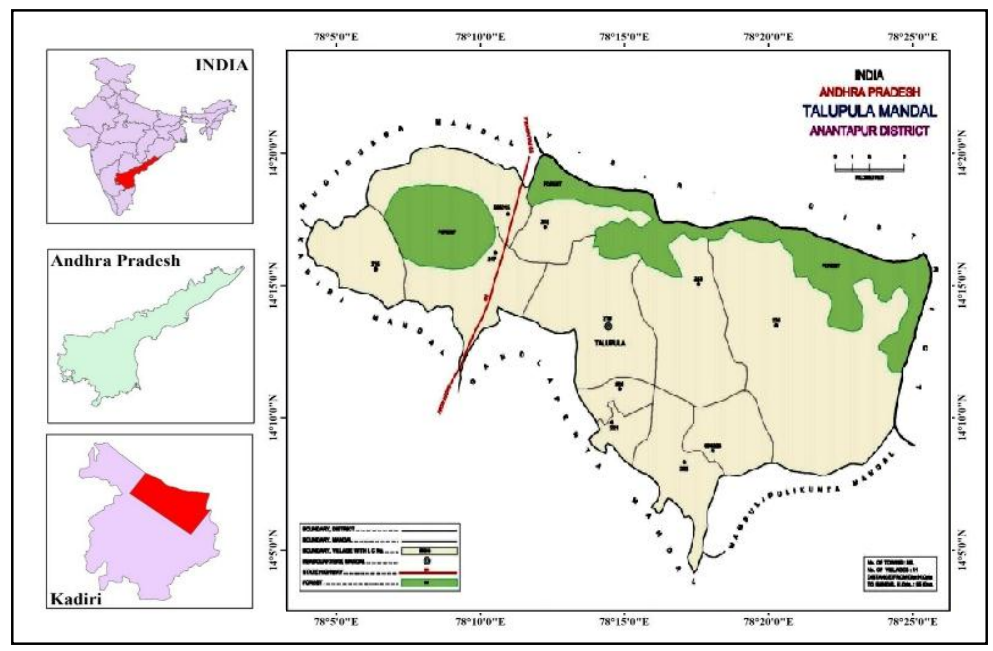

Fig. 1: Study area map of Talupula Mandal.

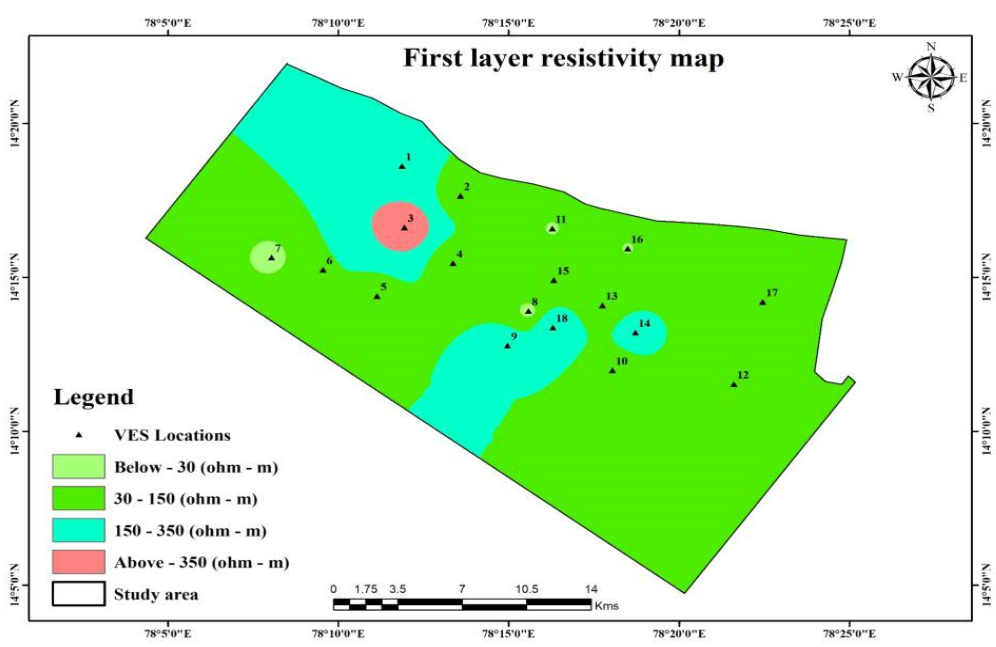

Fig. 2: First layer resistivity map. 
some are better at leading it. Resistivity is an assumption that enables examinations of how various materials permit or oppose flow (Bera \& Ahmad 2017, Singh et al. 2019). To make resistivity records meaningful, explicit units are used, and for a given size of material, there are equations for determining it and relating it to the obstruction in Ohms. Materials with a low resistivity that effectively lead electrical flow are known as channels (Arfan et al. 2020, Khan et al. 2018). Covers are those that do not effectively direct electrical flow, and these materials have a high resistivity.

\section{Electric Resistivity Survey}

Electrical resistivity surveys are carried out by passing a known electric current through the ground using two electrodes and calculating the potential differences between the other two potential electrodes. The potential variations may be changes due to the size, shape, and conducting capacity of the material in the subsurface, and the resistance is calculated based on the quantities of potential differences and the current applied (Abrams et al. 2018, Kaliraj et al.2018).

\section{Resistivity Layer Maps}

The resistivity of the study area has been separated into five layers. Each layer has its own significance and characteristics. It helps to identify the resistivity of each layer.

\section{Demarcating the Resistivity Layers in Groundwater Potential Region Using Resistivity Survey}

\section{First Layer Resistivity Map}

In the study area, the first layer is the topmost layer, which is the weathered material of basement rock. A low value of resistivity in the first layers is referred to as clayey formation and it is not good for surface recharge potential.
Resistivity ranges of 30-150 are good for surface recharge structures like percolation ponds and lakes. The first layer resistivity is shown in Fig. 2.

\section{Second Layer Resistivity Map}

The second layer is the weathered formation of basement rock. The second layer's low resistivity is associated with the presence of highly weathered areas and is suitable for recharging through injection wells. Highly weathered areas can be seen in the northern section of the study area. The second layer resistivity map is shown in Fig.3.

\section{Third Layer Resistivity Map}

The third layer is circulated by fractured formation. An injection well is used to place fluid underground into porous geologic formations. Water can be recharged directly into the location (subsurface) through deep injection wells. Most of the study area is occupied with higher resistivity areas and it is the base of the study area. Locations 6 and 12 may be recharged in third layer conditions. Fig. 4 shows the resistivity map of the 3rd layer.

\section{Fourth Layer Resistivity Map}

The fourth layer is the secondary fracture formation. A borewell structure can be built in this location. The entire study area has high resistivity; it is not suitable for recharging expect in location numbers 6,13 , and 14 . The layer one by one defines the significant characteristic of the layer. The more it goes deeper the more the compacted layers are found. Fig. 5 . shows the resistivity map of the fourth layer.

\section{Fifth Layer Resistivity Map}

The fifth layer is known as secondary fracture formation with

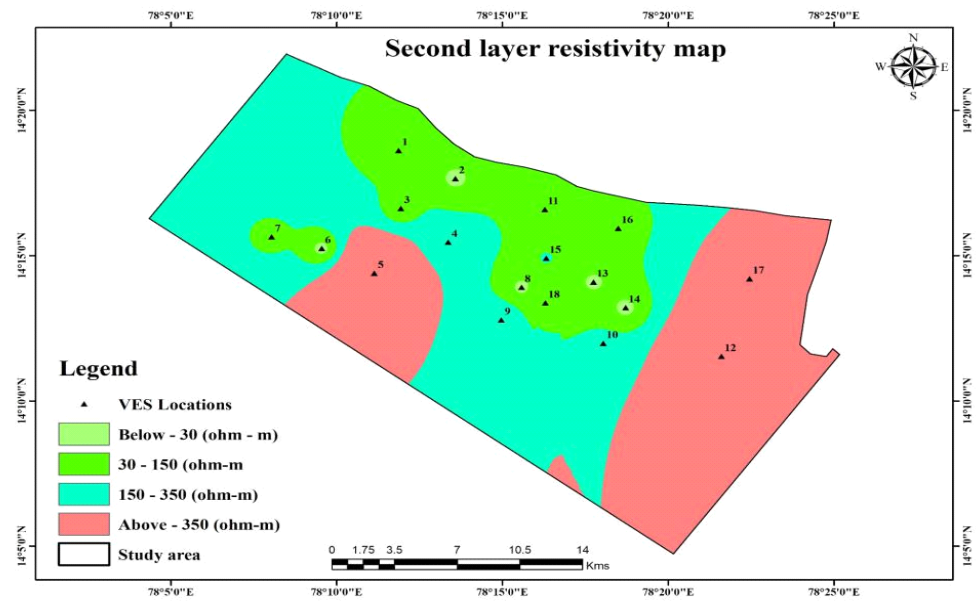

Fig. 3: Second layer resistivity map. 


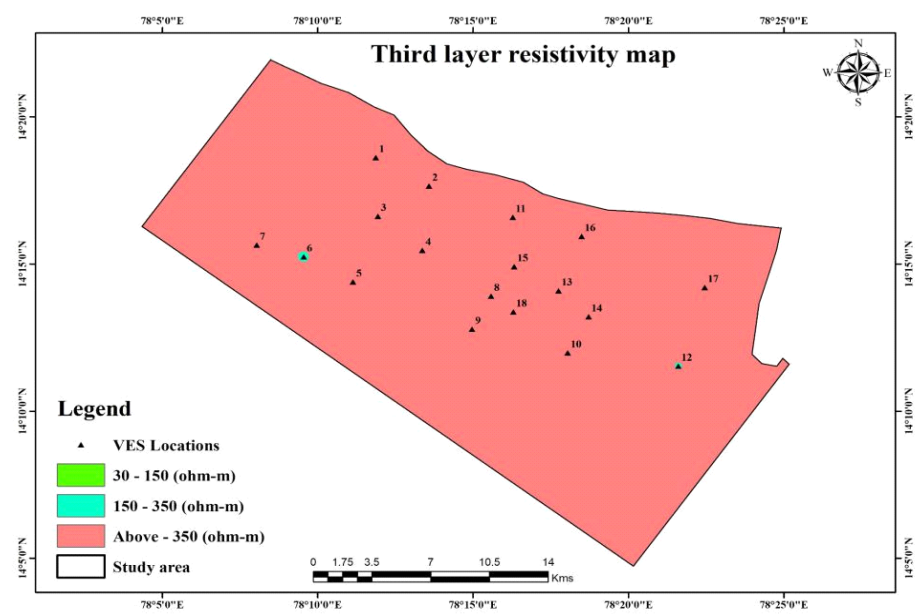

Fig. 4: Third layer resistivity map.

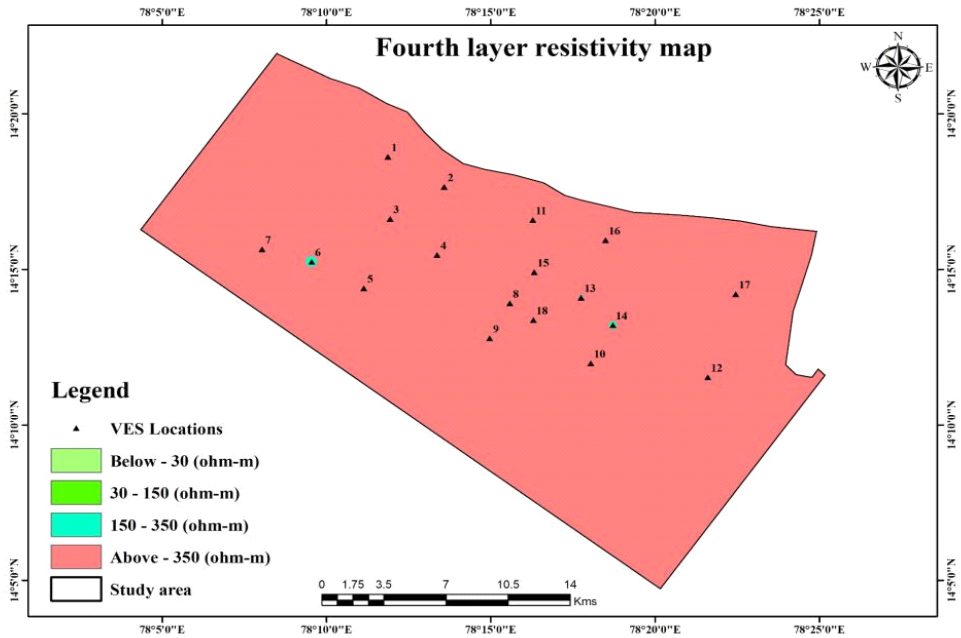

Fig. 5: Fourth layer resistivity map.

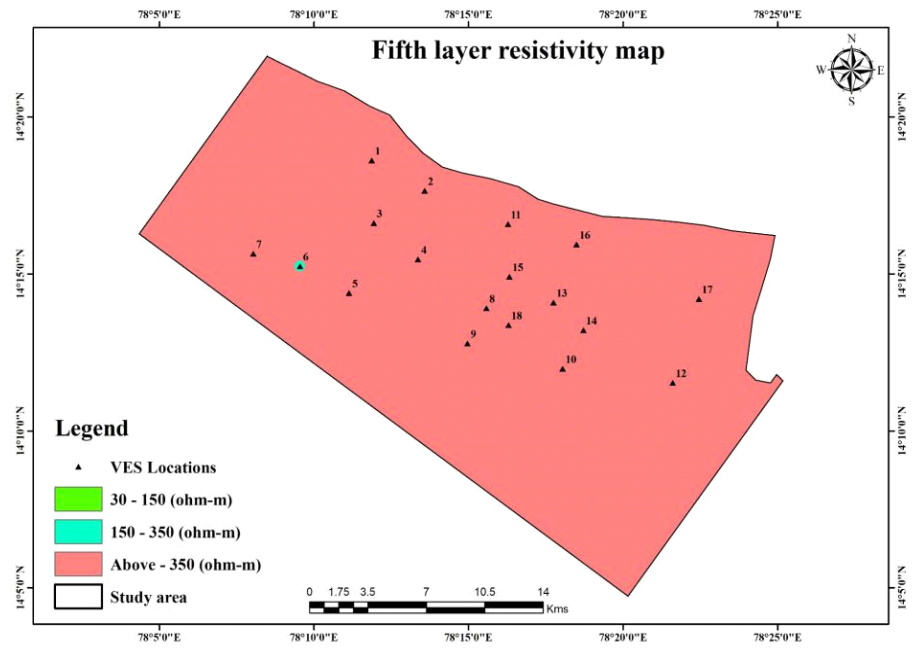

Fig. 6: Fifth layer resistivity map. 
a non-potential stage, and it is also used to build a recharge bore well structure. This fracture exists at location number 13, and this zone can only be recharged. Fig. 6. shows the resistivity map of the fifth layer.

\section{Thickness Layer Map}

Thickness is also an important aspect of groundwater recharge. The study area was divided into four layers based on its thickness. It defines the depth of each layer. Every layer has its own significance and characteristics.

\section{Demarcating the Thickness Layers in Groundwater Potential Region Using Resistivity Survey}

Groundwater recharge is high in densely populated areas. Locations 15, 16, and 17 in this layer have a better chance of being recharged from surface resources. The thickness map of the first layer is shown in Fig. 7.

\section{Second Layer Thickness Map}

The second layer shows the weathered zones. Thickness is more in this layer. Hence, this layer is good for groundwater recharge. Injection wells are the most effective method of recharging. The weathered zone is defined as the superficial layer of Earth's crust above the water table that is exposed to atmospheric destructive agents and where soils develop. Fig. 8 shows the thickness map of the second layer.

\section{Third Layer Thickness Map}

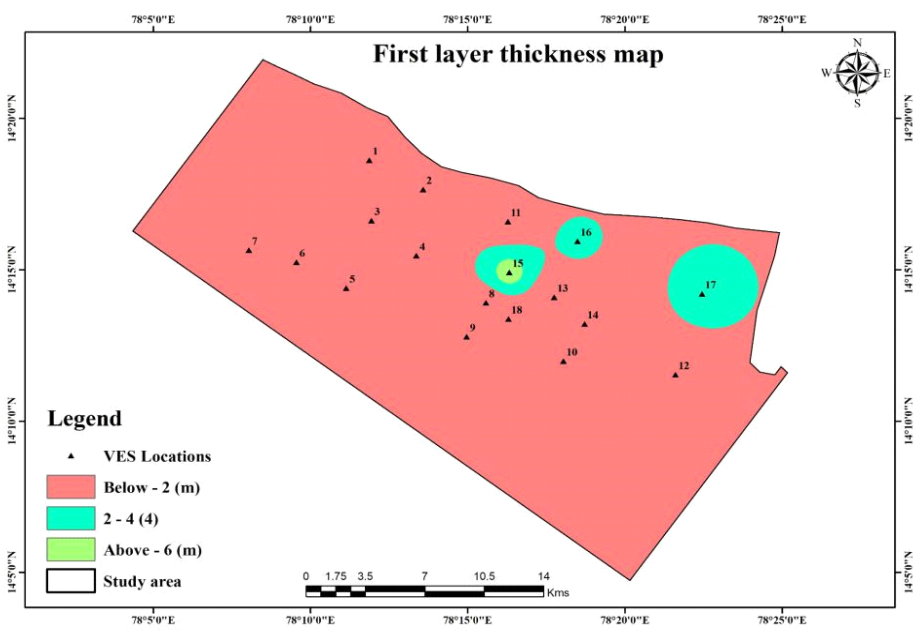

Fig. 7: First layer thickness map.

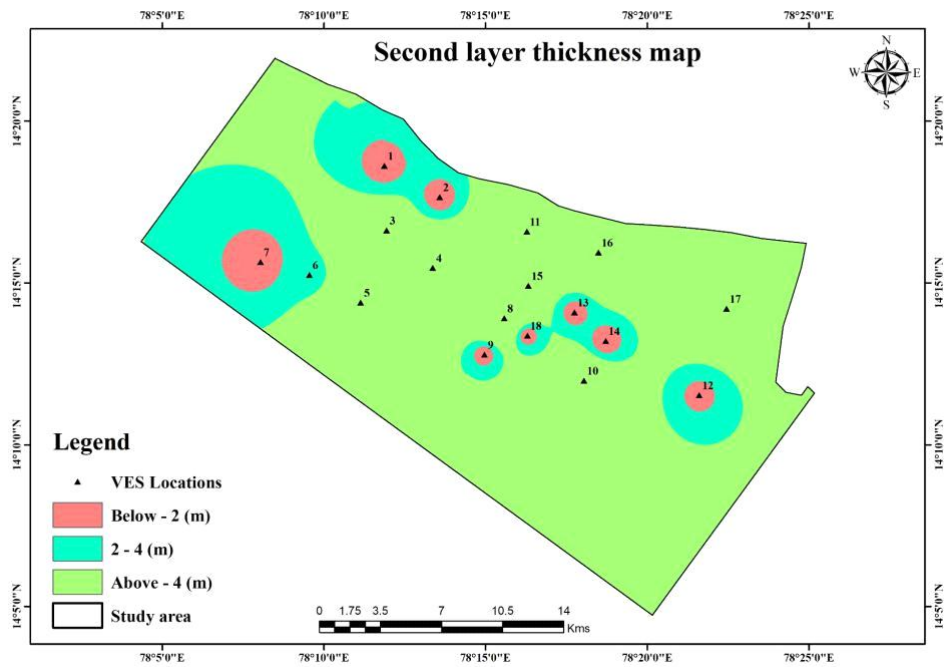

Fig. 8: Second layer thickness map. 


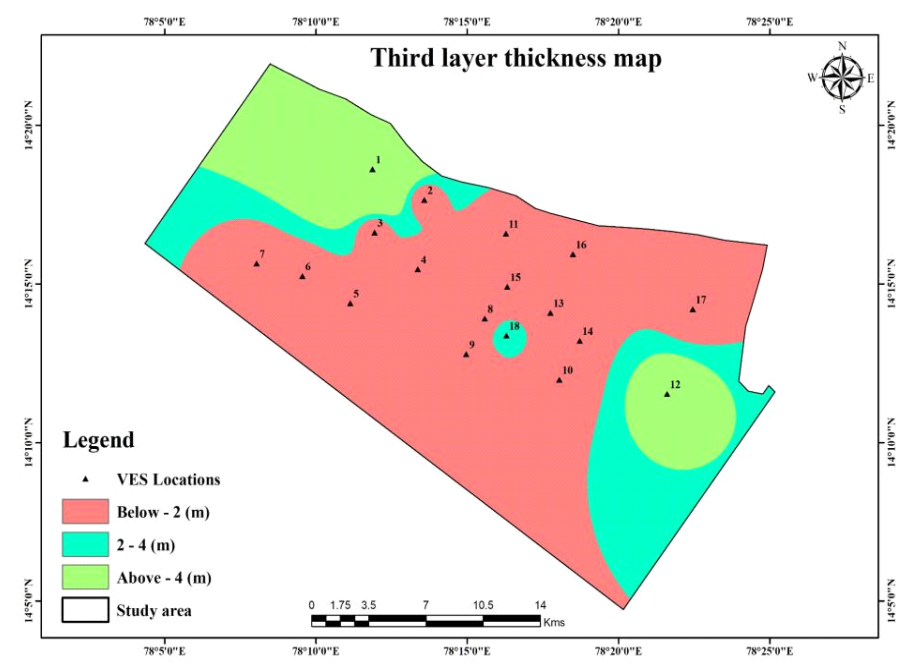

Fig. 9: Third layer thickness map.

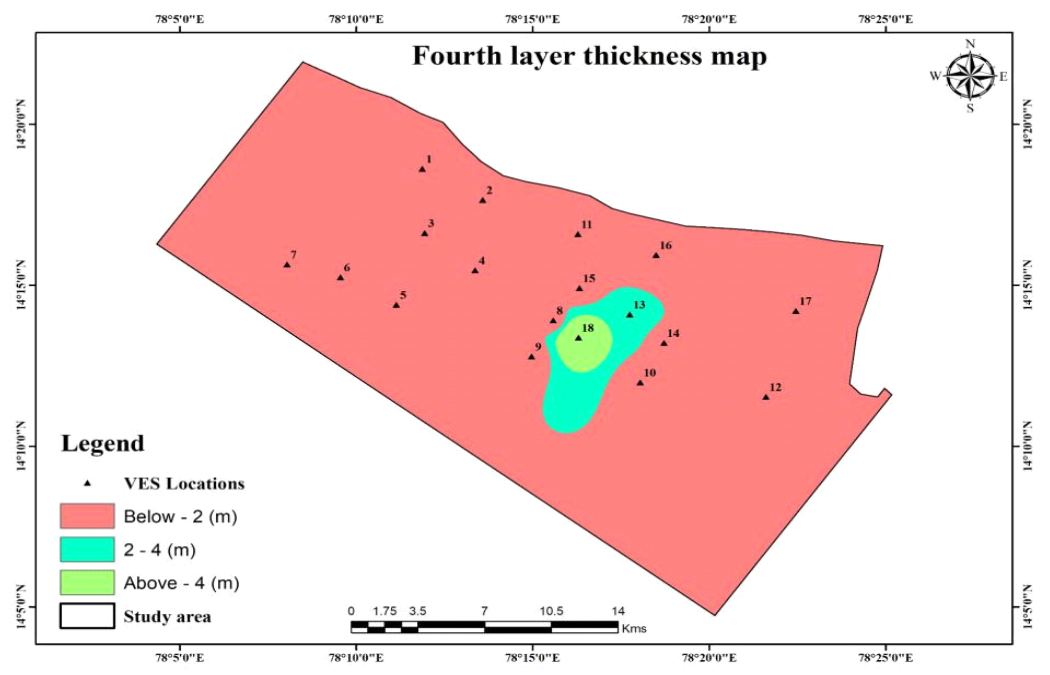

Fig. 10: Fourth layer thickness map.

In the third layer, recharging possibilities are very less because of its thickness. Location numbers 1, 12, and 18 are suitable for recharging. Fig. 9 shows the thickness map of the third layer.

\section{Fourth layer thickness map}

Except at site number 18, the recharging is essentially unsuitable in this layer due to lesser fracture thickness. Fig.10 shows the thickness map of the fourth layer.

\section{CONCLUSION}

This research has shown that a resistivity survey is useful to identify the groundwater potential zones in many possible ways. Several methodologies can be recommended for carry- ing out resistivity surveys of potential zones. Schlumberger's method is very easy and gives accurate output. As a result, groundwater potential zones for recharging groundwater structures were found among the 18 places in the study region, Talupulamandal of Toposheet Nos. $57 \mathrm{~J} / 3, \mathrm{~J} / 4, \mathrm{~F} / 14$, $\mathrm{F} / 15$. According to the resistivity survey, it is found that these seven locations Lakka Samudram, Gajjelappagaripalli, Bateripalli, Vepamanupeta, Gurramgundlapalli, Gangivaripalli, Poolavandlapalli, have more water potential for constructing groundwater recharge structures.

\section{REFERENCES}

Abrams, W., Ghoneim, E., Shew, R., LaMaskin, T., Al-Bloushi, K., Hussein, S., AbuBakr, M., Al-Mulla, E., Al-Awar, M. and El-Baz, F. 2018. 
Delineation of groundwater potential (GWP) in the northern United Arab Emirates and Oman using geospatial technologies in conjunction with simple additive weight (SAW), analytical hierarchy process (AHP), and probabilistic frequency ratio (PFR) techniques. J. Arid Environ., 157: 77-96.

Alwathaf, Y. and Mansouri, B.E. 2011. Assessment of aquifer vulnerability based on GIS and ARCGIS methods: A case study of the Sana' a Basin (Yemen). J. Water Resour. Prot., 3: 845-855.

Arfan, A., Zhijie, Z., Wanchang, Z. and Adil, D. 2020. Mapping favorable groundwater potential recharge zones using a GIS-based analytical hierarchical process and probability frequency ratio model: A case study from an agro-urban region of Pakistan. Geosci. Front., 11(5): 1805-1819.

Bera, S. and Ahmad, M. 2017. Delineation of groundwater potential zones in Dhanbad district, Jharkhand, using Remote Sensing and GIS Techniques. Int. Res. J. Eng. Technol., 03: 2395-0072.

Chandramohan, R., Kanchanabhan, T.E., Siva Vignesh, N. and Krishnamorthy, R. 2017. Integrated techniques to identify groundwater potential region in Palani Taluk, Tamilnadu, India using electric resistivity, remote sensing, and GIS techniques. ARPN J. Eng. Appl. Sci., 12(22): 63096319.

George, N.J., Obianwu V.I. and Obot, I.B. 2011. Estimation of groundwater reserve in the unconfined frequently exploited depth of aquifer using a combined surficial geophysical and laboratory techniques in the Niger Delta, South Nigeria. Adv. Appl. Sci. Res., 2(1): 163-177.
Hammouri, N., Amoush, H.A., Raggad, M.A. and Harahsheh, S. 2013. Groundwater recharge zones mapping using GIS: A case study in Southern part of Jordan Valley. Arab J Geosci., 7: 2815-2829.

Kaliraj, S., Chandrasekar, N. and Magesh, N. 2014. Identification of potential groundwater recharge zones in Vaigai upper basin, Tamil Nadu, using GIS-based analytical hierarchical process (AHP) technique. Arab. J. Geosci., 7: 1385-1401.

Khan, A.D., Ashraf, M., Ghumman A.R. and Iqbal, N. 2018. Groundwater resource of Indusplain aquifer of Pakistan investigations, evaluation, and management. Int. J. Water Resour. Arid Environ., 7: 52-69.

Singh, S.K., Zeddies, M., Shankar, U. and George, A.G. 2019. Potential groundwater recharge zones within New Zealand. Geosci. Front., 10(3): 1065-1072.

Srinivasamoorthy, K., Chidambaram, S., Vasanthavigar, M., Anandhan, P. and. Sarma, V.S. 2014. Geophysical investigations for groundwater in a hard rock terrain, Salem district, Tamil Nadu, India, Bull. Eng. Geol. Environ., 73: 357-368.

Vidhya, L. and Vinay, K.R. 2018. Identification of groundwater potential zones using GIS and remote sensing. Int. J. Pure Appl. Math., 119(17): 3195-3210.

Zeinelabidin, E., Hassan, R., Garamoon, K., Ahmed, S., Al Matari, M., Khalil, F. and Ebraheem, A.M. 2015. Application of earth resistivity, hydrogeochemistry, and isotope hydrology methods for assessment of groundwater recharge in two drainage basins in Northeastern United Arab Emirates. IOSR J. Appl. Geol. Geophys., 3(6): 01-13. 